\title{
Comprehending organizational functioning from a systems approach
}

\author{
Verlin B. Hinsz ${ }^{1, ~ *, ~ J a n e t ~ L . ~ S u t t o n ~}{ }^{2}$ \\ ${ }^{1}$ Dept. of Psychology, North Dakota State University, Fargo, ND, USA \\ ${ }^{2}$ USAF Material Command $711^{\text {th }}$ Human Performance Wing, Human Effectiveness Directorate, Wright-Patterson Air Force Base, OH \\ USA
}

Email address:

Verlin.Hinsz@NDSU.edu (V. B. Hinsz)

To cite this article:

Verlin B. Hinsz, Janet L. Sutton. Comprehending Organizational Functioning from a Systems Approach. International Journal of Economic Behavior and Organization. Vol. 1, No. 5, 2013, pp. 50-55. doi: 10.11648/j.ijebo.20130105.12

\begin{abstract}
Specialists in many fields need to describe how organizations under investigation operate and function. These specialists often try to categorize organizations by structural features that are important for understanding how the organizations function. This paper reports the results of a workshop that asked subject matter experts to generate a framework for describing the critical features underlying organizational functioning. The experts generated a set of 13 systems that reflected the key aspects of organizational functioning for the broad range of organizations. The experts and members of the client organization all agreed that the 13 systems provided an extremely valuable representation of organizational structure and functioning. The systems generated are useful for different types of specialists who examine organizations. Importantly, this analysis indicates that the systems are similar to those of the open-systems theory of organizations.
\end{abstract}

Keywords: Organizational Structure, Organization Functioning, Open Systems Theory of Organizations, Organization Systems, Organizational Characteristics

\section{Introduction}

Organizations are an important focus of research in management and psychology because they serve critical functions in people's lives [1]. Additionally, because people can perceive the structure of organizations, they tend to believe that organizational structure influences, and is related to, organizational functioning. We were tasked with trying to articulate organizational functioning and particularly to provide a framework that would describe organizational structure which would lead to an explanation of the relationship between structure and organizational functioning.

The relationship between organizational structure and organizational functioning has been a topic of research for decades (organizational theory, organizational behavior, organization sociology). However, research on the relationship between organizational structure and functioning has been relatively inactive since approximately 1980 [2]. Instead of furthering the conceptualizations of organizational structure, design, and function, research has focused on the characteristics of organizations that influence how they operate and function (e.g., centralization, environmental turbulence, diversity of the management team). Usdiken and Leblebici describe potential reasons why this research area has become inactive, but regardless of the reasons, the reality of the relative inactivity is apparent.

Prior to the current period of inactivity, there had been several decades in which the investigation of the relationships between organizational structure and functioning had been ongoing. Perhaps the most obvious aspect of this research was Weber's [3] delineation of bureaucracy as a more rational approach to organizational design. Weber's work was preceded by the theoretical work of Marx [4] and others. For example, Frederick Taylor [5] suggested a more direct way to influence organizational functioning was to engineer the job to maximize human production and eliminate inefficiencies. In a more recent period, the human relations approach to management [6] suggested putting the human element back into organizations rather than focusing merely on the positions that humans inhabit. MacGregor [7] extended these notions to suggest that the Theory $\mathrm{Y}$ approaches to organizational behavior would provide a more humane and beneficial way of directing organizational functioning. From Europe, the 
socio-technical approach [8] suggested that a broader view of organizations that included an emphasis on the environment and the means by which work was conducted needed to be considered. Subsequently, the consideration of Theory Z [9] suggested that elements of a Japanese approach to management that focuses more on consensus, a culture of quality, and explicit and implicit activities for the roles of worker and management could influence organizational functioning. All of these more conceptual and theoretical efforts provide a basis for much of our current understanding of the relationships between organizational structure and functioning. However, the key point is to recognize that there has been little analysis since about 1980 investigating of the relationship between structure and organizational functioning. Instead, investigations have turned from the more conceptual to the more empirical.

The recent decades have seen much empirical examination of how specific organizational characteristics of structure (e.g., size) have influenced organizational functioning. Woodward [10] focused on how the technological aspects of manufacturing organizations related to organizational structure. Thompson [11] provided a different view of how technology influenced organizational structures. In contrast to the influence of technology, other conceptualizations focused on the environment of the organization such as the socio-technical program of research [12]. Lawrence and Lorsch [13] also examined environmental differences that might impact organizational structure effectiveness. In particular, Lawrence and Lorsch describe what are considered two of the primary aspects of the environment: differentiation of departments and integration of activities. In addition to technology and environment, other conceptualizations have considered additional factors of an organization that could influence organizational structures and functioning (e.g., information processing approach; [14]). In combination, this more empirical research led to a generic structural contingency theory of organizational functioning. To describe structural contingency theory briefly, there is not one best way to design and structure organizations. The most effective organizational structure depends strongly on a variety of variables such as environmental uncertainty, competition from other firms, and technology.

As this brief review highlights, there has been a rich history of conceptualization on the relationships between organizational structure and functioning prior to 1980 but a paucity of attention since then. This is partially the result of a reframing of the question from the conceptual and theoretical focus to much more attention to the empirical relationship between organizational structure and organizational functioning. It is difficult to find current conceptual research on organizational structure and functioning. More importantly, the question remains of how organizational structure and organizational functioning influence each other. An understanding of the relationship between organizational structure and function is still required in certain domains. We intend to direct attention again to the relationship between organizational structure and functioning and demonstrate that the relationship is still important.

We will describe a study of organizational structure and organizational functioning. This study was commissioned to address a client's desire to understand the relationship between organizational structures and organizational functioning. We report the consensus achieved from a team of subject-matter experts knowledgeable about organizations. In the process of reporting this study, attention will be directed toward the open-systems approach to organizations [15] as an organizing framework.

\section{The Problem and Purpose}

We were approached by an agency to address the general question of how to conceptualize organizational structure to understand organizational functioning. The agency had a client organization that needed to understand this relationship and were particularly interested in how organizational structure influenced organizational decision making. The employees of the client organization conducted analyses of organizations and wrote reports detailing the characteristics, structure, and functioning of those organizations.

Organizational analysis is not unique to particular companies or organizations. Many individuals conduct analyses of organizations for a variety of purposes. Financial analysts study organizations and the organization's structure to determine how well the organization is functioning and the risks that would be inherent in investing in the organization. Similar concerns arise for philanthropic organizations making contributions to non-profit and non-governmental organizations. Insurance analysts study organizations to understand the risks of a particular policy as well as to determine the premium that should be charged to accommodate those risks. Archivists also study organizations so they can describe how it functioned and why it might have taken the actions it did. Historical analyses of economic, political, technological, and social trends would also be interested in the ways in which organizations are structured so that they can get a grasp of why the organization functioned the way it did (e.g., Mafia).

Clearly, the question of how organizations are structured and how structure influences functioning is still critically important for various analytic efforts for comprehending organizations. To more closely address the questions of the client for which the agency commissioned this study, we determined to examine the best ideas available for conceptualizing the relationship between organizational structure and organizational functioning. 


\section{Method}

\subsection{Participants}

The first author was contracted to organize a workshop for the agency. This study involved the contributions of five subject matter experts (SMEs), all who had current or previous employment in academic settings. In addition, the contract from the agency provided for two facilitators to help with the workshop. The facilitators provided the facility for the workshop and set the ground rules for the workshop interaction. Three high level members of the client organization attended the workshop, one of whom was the unit manager and two were senior analysts. The sponsoring agency also had two members in attendance as contract monitors. Three other members of the sponsoring agency attended to gain information about organizational structures and functions that might be relevant to other clients of the agency.

\subsection{Workshop Objectives}

The workshop had a number of objectives which were specified before the workshop began. Members of the workshop's sponsoring agency and the workshop organizer met on three occasions to define the objectives for the workshop. As a function of these meetings, the overriding goal was "To identify a typology or set of typologies of organizations that will serve as a foundation to help staff analysts." That is, the analysts desired a typology that would help them identify the type of organization under investigation and provide guidance about the characteristics of organizations. A more general goal was to identify typologies and observable characteristics of organizational structures to help explain the way organizations function.

As a function of the over-riding goal of the workshop, it was recognized that a number of related goals would need to be considered as well as challenges that the members of the workshop faced as they addressed these goals. The related goals entailed: (1) being able to reliably differentiate among the wide array of organizational structures, (2) to identify indicators of organizations that can be observed which can help identify and 'type' an organization, and (3) detail the characteristics and processes of the organizational types that might reflect the operation and function of the organization type (and which are likely to influence the way the organization decides and acts). In order to appreciate the value of these goals, it was also necessary to recognize the important challenges of: (1) that numerous different organizational typologies have been suggested over the years, (2) that these typologies are often based on distinctions that are not observable, (3) the existing typologies are at different levels of specificity, and (4) the existing typologies are tailored to different types of organization (e.g., manufacturing, service industries) and focus on different observable characteristics which may not be generalizable to the wide range of organizations being considered by the analysts.
In addition to the goals of the workshop, a set of objectives were also defined. First, the workshop should involve an initial review of existing typologies from the literature and understand the characteristics upon which organizations are categorized within each typology. Second, the workshop should entail a review the known characteristics and processes of organizations that are believed to influence their defining features even if they do not fit an existing 'type.' Third, the workshop involved discussion of the characteristics of an organization's structure that are typically known by or observable by staff analysts. Finally, the workshop should consider (a) the multiple existing typologies (b) to develop a comprehensive (and hopefully integrated) typology (c) that distinguishes among organizations based on characteristics that can be identified based on indicators and (d) that are likely to influence organizational decisions and actions.

Based on these various goals, objectives, and challenges, the organizer and members of the sponsoring agency developed a one and half day agenda for the workshop. Additionally, all individuals invited to participate in the workshop were sent a number of preparatory materials to read in advance of the workshop. These materials included a description of organizational structure and functioning from a typology perspective. The materials also included excerpts from a task analysis that described how the analysts currently performed their duties. Another document was a description of how the analysts viewed their jobs. Finally, a document outlining the vague organizational typology currently in use by the analysts was provided to the subject matter experts. The subject matter experts invited to the workshop received a substantial honorarium and were reimbursed for their travel to the workshop location.

\subsection{Workshop Process}

After introductions among the participants of the workshop early on the first day, the facilitators described the features of the facility as well as some general ground rules for interacting during the workshop. Then the organizer presented an overview of the workshop goals and purposes as well as a conceptualization of the general nature of the problem the staff analysts face. He then suggested that it would be useful to consider the organization typologies that might be appropriate, the characteristics of organizations which might contribute to the development of a comprehensive typology, and to differentiate the processes of organizations from their structure.

Next, the analysts presented the problems they faced in describing organizations as well as features of the work they performed. This involved an extensive dialogue with the subject matter experts who tried to better understand features of the analysts' work. After this extensive dialogue and the opening problem description, the workshop organizer asked the subject matter experts (SMEs) to delineate a few of the typologies that already exist in the 
literature (e.g., matrix, divisional). This description of existing typologies veered into more elucidation of the characteristics that might help differentiate different types of organizations. As the discussion of organizational characteristics evolved, the SMEs also suggested important organizational processes which were distinguished from organizational characteristics and types.

After several hours of listing and describing different organizational types and typologies, organizational characteristics and processes, it became apparent that the descriptive nature of typologies was not consistent with the true objectives of the staff analysts. The analysts were not just interested in the typology but were more concerned with the way the typology would explain how organizations function. As the discussion continued, some SMEs starting using terms that reflected organizational systems to describe organizational functioning (e.g., reward system, command system). The notion of a systems view of organizational functioning resonated strongly with the analysts. Consequently, with the agreement of members of the sponsoring agency, the focus of discussion shifted to a characterization of organizations based on the systems that describe how organizations function. The systems approach seemed to better address both the function and descriptive aspects of organizations that the staff analysts desired.

The workshop organizer asked the SMEs if there was any systems approach to organizations that would meet the objectives of the workshop. The SMEs pointed out that the open-systems approach of Katz and Kahn [15] would be of value but it was at too high a level of abstraction to be of much use to the analysts without further specification. Consequently, the organizer asked the SMEs to help produce an inclusive list of systems of organizational functioning. The analysts were asked to evaluate the inclusion of a system into the list to make sure it represented the views of organizations for which they had responsibility.

In a sequential fashion, 13 different organizational systems were added to the list (see Table 1). In alphabetical order, these systems were labeled as: Administrative Control, Command Authority, External Relations, Financial/Budgeting, Indoctrination/Socialization, Information Systems, Intelligence, Knowledge/Skills/Abilities, Material Acquisition, Planning \& Development, Production/Transformation, Reward/Motivation, and Support/Maintenance. A workshop participant would offer a system and describe

which aspects and functions of an organization it was meant to represent. After a participant offered a system for inclusion, discussion would entail which would often elaborate on the original notions. The workshop organizer made sure that each system included would be distinct from the other systems in critical ways. Also, the SMEs and analysts were asked whether the inclusion of the nominated system would enhance the understanding of organizational functioning. When the final set of 13 systems was specified, all participants were asked repeatedly whether all the reasonable systems were included in the list and whether the list was sufficient to explain most of the functioning of organizations. Also, the workshop organizer asked repeatedly whether any of the systems included in the list should be deleted because they did not represent a functioning aspect of organizations or were redundant with other included system. No further system was added or deleted from this list after the 13 were elicited and described.

After the participants had some time to contemplate the list of systems and discuss the characteristics and implications of the systems, focus shifted to a description of the meaning behind the systems listed and particularly how these systems would influence organizational functioning.

Table 1. Listing of Systems of Organizational Functioning Produced During the Workshop

\begin{tabular}{|c|c|}
\hline System Label & Brief Description of the System \\
\hline Administrative Control & $\begin{array}{l}\text { The articulated operating procedures and regulating structures that guide the processes of the organization's routine } \\
\text { activities }\end{array}$ \\
\hline Command Authority & Leadership, management, administration, chain of command, that moves individuals in the organization toward objectives \\
\hline External Relations & $\begin{array}{l}\text { Engagement with entities outside of the organization; alliances, allies, suppliers, etc. that are sought to further } \\
\text { achievements }\end{array}$ \\
\hline Financial/Budgeting & Acquiring, monitoring and regulating the funds and related resources that allow the organization to pursue objectives \\
\hline Indoctrination/Socialization & The ways that individuals become identified members of the organization as well as internalize its norms and ideology \\
\hline Information Systems & The ways the organization directs, controls, stores, monitors, and distributes information and the technology used to do so \\
\hline Intelligence & The means and mechanisms the organization uses to gain information about entities and action outside the organization \\
\hline Knowledge/Skills/Abilities & The ways the organization recruits or trains the specific talents that the organization needs from among its members \\
\hline Material Acquisition & $\begin{array}{l}\text { The procedures the organization uses to acquire the tangible resources required to produce the goods and services it } \\
\text { delivers }\end{array}$ \\
\hline Planning \& Development & $\begin{array}{l}\text { The strategic functions the organization pursues to determine its current actions as well as to define and pursue future } \\
\text { goals }\end{array}$ \\
\hline Production/Transformation & The processes, technologies, and mechanisms by which the organization produces goods and services to acquire resources \\
\hline Reward/Motivation & $\begin{array}{l}\text { The tangible and intangible means by which the organization instigates, continues, regulates, and terminates member } \\
\text { efforts }\end{array}$ \\
\hline Support/Maintenance & The ways the organization sustains, rejuvenates, reinforces, corrects, and cares for its practices, personnel, and products \\
\hline
\end{tabular}


By elaborating on the systems, a clearer understanding of the meaning of the systems was realized. Moreover, the analysts were given an opportunity to probe the SMEs about how the systems would represent aspects of organizations for which they were responsible for analyzing. This discussion lasted several more hours and more comprehension of the systems was gained by the analysts based on discussions with the SMEs.

\subsection{Client Evaluation}

When the workshop was concluding, members of the sponsoring agency and the staff analysts were asked if they found the workshop and the systems approach to organizational functioning that had been produced to be useful. The analysts said that previous to the workshop, the vague organizational typology they were using provided them with a $15 \%$ solution. However, the systems approach to organizations provided an $85 \%$ solution. Moreover, the analysts said the discussion early in the workshop was valuable to help understand organizations. Additionally, an analyst stated that the workshop identified important aspects of organizational functioning that the analysts had overlooked. Another analyst stated that s/he had been involved in numerous workshops in the last decade and this workshop was the only one that provided useful information. Based on these statements and similar ones by the contract monitors' there was strong agreement that the workshop was successful.

Table 2. Listing of Organizational Characteristics Generated During the Workshop

\begin{tabular}{l}
\hline Organizational Characteristic \\
\hline Size \\
Organizational Culture \\
Organizational History \\
Coherence/Fissures \\
Power and Influence \\
Dispersement \\
Homogeneity/Heterogeneity \\
Current \& Future Status \\
Dynamism/Stability/Turbulence \\
Capabilities \& Competencies \\
Organizational Identity \\
Inter-Organizational Network
\end{tabular}

\section{Results}

The primary result of the workshop is the list of organizational systems that was generated. This list is presented in Table 1. The list is quite inclusive and represents various aspects of features of organizations. The view of organizations was not limited to manufacturing or service organizations, but was intentionally specified to be all manner of organization (e.g., large, small, multinational, NGO, private, public). Although the list is slightly long, it was meant to be inclusive so that it would help explain the functioning of a large assortment of organizations. Moreover, it was intended to be comprehensive. However, the list of systems is not the integrative typology that was initially anticipated to be a result of the workshop.

In addition to the list of organizational systems, the workshop participants also generated a list of characteristics of organizations that might be relevant for understanding organization functioning. This list of characteristics (Table 2) highlighted features that were not captured by the list of systems but that might be important for further discussion. Again, the terminology did not always follow the jargon of organizational science, but instead reflected general terms that were sensible to the analysts participating in the workshop.

Subsequent to the workshop, the workshop organizer and a contract monitor attempted to establish links between the systems generated as part of the workshop with the existing literature on systems in organization. In particular, each read Katz and Kahn [15] to determine how well the systems generated mapped on to the description of the open-systems approach. In the process, it became evident to both the organizer and contract monitor that there was substantial overlap between the systems generated in the workshop and the systems that were discussed throughout Katz and Kahn's book. Although Katz and Kahn focused on five subsystems of organizations, their book included descriptions of a number of other subsystems in organizations which contributed to organizational functioning but did not receive the same attention as the five subsystems in their framework.

The workshop organizer and the contract monitor independently attempted to relate the systems produced in the workshop with the five subsystems which were the focus of the Katz and Kahn open-systems framework. There was much agreement between the two representations, so consensus was achieved on one framework which is presented in Table 3. Table 3 presents an organization of the systems generated at the workshop and how they were perceived to map onto Katz and Kahn's subsystems [15].

Table 3. Framework for Representing the Mapping of the Organizational Systems Generated at the Workshop to the Organizational Subsystems of Katz and Kahn

\begin{tabular}{ll}
\hline $\begin{array}{l}\text { Katz and Kahn's } \\
\text { Organizational Subsystems }\end{array}$ & $\begin{array}{l}\text { Organizational Systems } \\
\text { Generated at Workshop }\end{array}$ \\
\hline Production/Technical & Production/Transformation \\
& Material Acquisition \\
Maintenance & External Relations \\
& Intelligence \\
Adaptive & Planning \& Development \\
& Indoctrination/Socialization \\
& Knowledge and Skills \\
Supportive & Reward/Motivation \\
& Support/Maintenance \\
& Administrative Control \\
& Command Authority \\
& Financial/Budgeting \\
Managerial & Information Systems \\
\hline
\end{tabular}




\section{Discussion and Conclusions}

Although the relationship between organizational structure and organizational functioning has had a long history, there has been a relative neglect of this issue in recent research in organizational science. However, the importance of the relationship between organizational structure and organizational functioning has not declined. Rather, there are new places in which it has become important to understand this relationship. Our purpose in conducting this research effort was to address the relationship for analysts who need to understand how organizations function based on observable aspects of the organization's structure. Responses from observers and participants after the workshop suggest that the workshop was successful in fulfilling the ultimate goals of the clients.

The workshop produced a list of 13 systems of organizational functioning. This systems approach is quite general and reflects aspects of the wide range of organizations. Consequently, this systems approach might be useful for other considerations of organizational structure and functioning. The responses from the members of the workshop and the staff analysts in particular suggest this systems approach is quite valuable to them. So, it might also be valuable for other types of analysis for which an understanding of organizational functioning is important. This systems approach can be used to explore how the systems might contribute to the understanding of how decisions are made in organizations given that Katz and Kahn [15] do describe this relation. It may also take much more effort, but it may be possible to develop a more integrative framework of organizational systems, structure, and functioning predicated on the systems approach that resulted from the workshop. Although it might be too ambitious a goal for this research effort, we hope that this report of our attempts to understand the relationship between organizational structure and systems with organizational function might spur future research which will reinvigorate a somewhat dormant approach to the study of organizations.

\section{References}

[1] J.B. Miner, Organizational behavior 2: Essential theories of process and structure. Armonk, NY: M.E. Sharpe, 2006.

[2] B. Usdiken and H. Leblibici, "Organization theory," in Handbook of Industrial, Work, and Organizational Psychology, vol. II, N. Anderson, D. S. Ones, H. K. Sinangil, and C. Viswesvaran, Eds. Thousand Oaks, CA: Sage, 2002, pp. 377-397.

[3] M. Weber, Economy and society. New York: Bedminster Press, 1968.

[4] K. Marx, Das Kapital: A critique of political economy. Washington, D.C.: Regnery Gateway, 1996.

[5] F.W. Taylor, The principles of scientific management. New York: Harper Bros., 1911.

[6] F.J. Roethlisberger and W.J. Dickson, Management and the worker. Cambridge, MA: Harvard University Press, 1939.

[7] D. MacGregor, The human side of enterprise. New York: McGraw-Hill, 1960.

[8] F.E. Emery and E.L Trist, Towards a social ecology. New York: Plenum Press, 1973.

[9] W.G. Ouchi, Theory Z: How American business can meet the Japanese challenge. Reading, MA: Addison-Wesley, 1981.

[10] J. Woodward, Industrial organization: Theory and practice. London: Oxford University Press, 1965.

[11] J.D. Thompson, Organizations in action. New York: McGraw-Hill, 1967.

[12] W.A. Pasmore, Designing effective organizations: The sociotechnical systems perspective. New York: Wiley, 1988.

[13] P. Lawrence and J.W. Lorsch, Organization and environment. Boston, MA: Harvard Business School Division of Research, 1967.

[14] J.R. Galbraith, "Organizational design: An information processing view.” Interfaces, vol. 4, pp. 28-36, 1974.

[15] D. Katz and R.L. Kahn, The social psychology of organizations, 2nd ed. New York: John Wiley \& Sons, 1978. 